\title{
The incidences of other primary cancers in patients with mycosis fungoides and Sézary syndrome
}

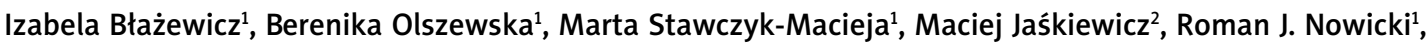 \\ Małgorzata Sokołowska-Wojdyło ${ }^{1}$
}

${ }^{1}$ Department of Dermatology, Venereology, and Allergology, Medical University of Gdansk, Gdansk, Poland

2Department of Biology and Pharmaceutical Botany, Faculty of Pharmacy, Medical University of Gdansk, Gdansk, Poland

\author{
Adv Dermatol Allergol 2021; XXXVIII (2): 289-294 \\ DOI: https://doi.org/10.5114/ada.2021.106205
}

\begin{abstract}
Introduction: Cutaneous T-cell lymphomas (CTCLs) are a diverse group of non-Hodgkin's lymphomas with malignant T lymphocytes infiltrating the skin. Mycosis fungoides (MF) and Sézary syndrome (SS) belong to the group of CTCLs, among others. In previous studies it was suggested that primary cancers more often occur in patients with cutaneous lymphoma.

Aim: To analyse the incidence of other malignancies in CTCL patients.

Material and methods: The evaluation of the coexistence of primary malignant neoplasms in CTCL patients was conducted by analysis of the patients' database, with diagnosis of mycosis fungoides and Sézary syndrome, treated in the Dermatological Department of the Medical University of Gdansk between 2010 and 2018.

Results: Among CTCL patients, 177 were diagnosed with MF/SS (stage MFIA 37.61\%, MFIB 30.77\%, MFIIA 0.85\%, MFIIB $11.11 \%$, MFIII 8.55\% MFIV 4.27\%; SS 6.84\%). The group was characterized by a male-to-female ratio of $1.21: 1$. $16.94 \%$ of MF/SS patients had one co-existing cancer, while $1.13 \%$ of patients had 2 co-existing cancers; the most common were basal cell carcinoma, lymphomatoid papulosis, lung cancer, and B-cell lymphoma. The obtained data highlight that MF/SS is associated with increased risk of cancer.

Conclusions: Our study suggests that special attention should be paid to careful examination of CTCL patients what force to perform solid clinical examination, the X-ray chest examination, abdomen USG, mammography, and others, even in early stages of MF/SS. Clinicians should be aware of the coexistence of other neoplasms such as lung, skin, and breast cancer.
\end{abstract}

Key words: mycosis fungoides, Sézary syndrome, lymphomas, cancer.

\section{Introduction}

Primary cutaneous T-cell lymphomas (CTCLs) are a heterogeneous group of lymphoproliferative disorders derived from CD4+ lymphocytes. Mycosis fungoides (MF) is the most common type. Cutaneous manifestations are generally the first sign of the disease, including erythematous, scaly patches, plaques, and tumorous lesions, as well as erythroderma. The aetiology of CTCL is not fully explained, although there are many hypotheses that implicate, for instance, occupational or environmental exposure, other forms of chronic antigenic stimulation, and viral infection. The annual incidence of CTCL varies between 0.4 to 1.0 per 100,000 people in the population. The prognosis of the disease in the majority depends on the extent of skin, blood, lymph node, and visceral organ involvement, along with advanced age and systemic extension.

The standard treatment is based on skin directed therapy (highly potent glucocorticosteroids, topical retinoids, mechlorethamine, phototherapy, radiotherapy) as well as systemic therapies, including extracorporeal photopheresis, bexarotene, methotrexate, biological response modifiers such as interferon- $\alpha$, and allogenic stem cell transplantation.

It has been suggested that MF patients are at higher risk of developing other malignancies, especially haematological ones such as B-cell non-Hodgkin's lymphomas [1, 2], melanoma [1], lung [3], colon [3], and urinary tract

Address for correspondence: Izabela Błażewicz, Department of Dermatology, Venerology, and Allergology, Medical University of Gdansk, 17 Smoluchowskiego St, 80-214 Gdansk, Poland, phone: +48 585844 028, e-mail: izabela.blazewicz@gumed.edu.pl Received: 16.09 .2019 , accepted: 20.11.2019. 
cancers [1], compared to healthy individuals. However, the increased risk of these neoplasm can be related to exposure to chemical carcinogens (chemical-related cancers, e.g. urinary bladder cancer), the potential aetiological factors of MF are still being discussed. Patients with a second malignancy preceded by MF occurrence are often exposed to phototherapy, local irradiation, and electron beam therapy, as well as chemotherapy. These therapies reveal the potential to generate an intense immune response resulting in chronic systemic inflammation. Moreover, they can induce direct or indirect DNA damage, which is also associated with increased risk of malignant transformation. Presumably, the second malignancy in CTCL patients can also develop due to the decreased cell-mediated immune response of $\mathrm{T}$ lymphocytes.

\section{Aim}

The main purpose of the study was to analyse the incidence of other malignancies in CTCL patients.

\section{Material and methods}

The aim of the study was to analyse the incidence of other malignancies in patients with CTCL. Among all those included in the study, 177 individuals were diagnosed with MF or Sézary syndrome (SS). The patients were enrolled to the study during their visits in the Outpatient Clinic and hospitalization in the Department of Dermatology, Venereology, and Allergology in Gdansk (Medical University in Gdansk) from January 2010 to November 2018. The MF/SS diagnosis was confirmed by

Table 1. Clinical characteristics of patients with mycosis fungoides (MF) and Sézary syndrome (SS), and patients with co-existing cancers

\begin{tabular}{lcc}
\hline Variable & $\begin{array}{c}\text { Patients with } \\
\text { MF/SS }\end{array}$ & $\begin{array}{c}\text { Patients with MF/ } \\
\text { SS and co-existing } \\
\text { cancers }\end{array}$ \\
\hline Total $n$ & 177 & 32 \\
\hline Age [years]: & & \\
\hline Female & $10-88(59.1)$ & $37-80(59.7)$ \\
\hline Male & $21-88(60.4)$ & $49-92(66.8)$ \\
\hline Sex: & & \\
\hline Female & 80 & 14 \\
\hline Male & 97 & 18 \\
\hline Male-to-female ratio & $1.21: 1$ & $1.28: 1$ \\
\hline & MFIA 37.61 & MFIA 54.84 \\
& MFIB 30.77 & MFIB 19.35 \\
& MFIIA 0.85 & MFIIA 0 \\
MFIIB 11.11 & MFIIB 6.45 \\
Stage of MF/SS (\%) & MFIII 8.55 6.45 \\
& MFIV 4.27 & MFIV 0 \\
& SS 6.84 12.91 \\
\hline
\end{tabular}

histopathological examination. The following information were recorded: date of birth, age at onset of MF/ SS, date of diagnosis, stage at diagnosis, and methods of treatment. The clinical database of the patients was checked to evaluate the coexistence of CTCL and other primary malignant neoplasms. Clinical characteristics are shown in Table 1.

\section{Results}

During the whole study 177 patients were diagnosed with MF/SS. There were 97 male and 80 female patients with a male-to-female ratio of $1.21: 1$. One co-existing cancer was diagnosed in $16.94 \%$ of CTCL patients (30 patients), and 2 co-existing other cancers were found in $1.13 \%$ (2 patients). In this case the male-to-female ratio was $1.28: 1$, with 18 and 14 patients, respectively. Taking into account the whole group of patients with coexisting cancers, the most common were basal cell carcinoma (BCC) and lymphomatoid papulosis, which were found in $15.63 \%$ of individuals (Table 2). The second was lung cancer, which affected $12.50 \%$ of patients, and the third was B-cell lymphoma, which accounted $9.38 \%$ of all neoplasms found in MF/SS patients. Nevertheless, when taking into account the distribution by sex (Table 3), the situation was slightly different [4-7]. For female patients the most common were BCC and breast cancer (14.29\% independently), while for men the most common was lymphomatoid papulosis (22.22\%). It should be highlighted that 2 co-existing cancers were found in one female and 1 male patient: kidney cancer and lymphomatoid papulosis, and B-cell lymphoma and teratoma malignum, respectively.

\section{Discussion}

The results of our study have supported previous findings concerning increased risk of second primary malignancy development, especially BCC, Hodgkin's lymphoma, chronic leukaemia, and lung cancer, in patients with MF and SS. Previous epidemiological data revealed that the factors associated with the increased risk of secondary solid tumours are: stage IV of the disease, the presence of lymphomatoid papulosis, and duration of the disease (more than 10 years). Furthermore, for the vast majority of the patients, secondary malignancies occurred within the first year of the diagnosis of MF (60\%) [8]. According to Cengiz et al., older age, higher stage of MF, and the presence of lymphomatoid papulosis are factors associated with increased risk of the coexistence of two other malignancies besides MF [8]. In our study, only 2 patients with MF were diagnosed with co-existing kidney cancer and lymphomatoid papulosis, and B-cell lymphoma and teratoma malignum, respectively.

According to Goyal et al., patients with MF are at increased risk of developing second malignancies, par- 
Table 2. The incidence (\%) and site of other primary cancers in patients with MF/SS $(n=32)$

\begin{tabular}{lllll}
\hline Other primary cancer & Metachronous & Pre/synchronous & Total & Percentage (\%) \\
\hline Lung cancer & 3 & 1 & 4 & 12.50 \\
\hline Basal cell carcinoma & 5 & 0 & 5 & 15.63 \\
\hline Breast cancer & 0 & 1 & 2 & 6.25 \\
\hline Ovarian cancer & 0 & 0 & 2 & 3.13 \\
\hline Kidney cancer & 2 & 0 & 2 & 6.25 \\
\hline Blader cancer & 2 & 0 & 1 & 6.25 \\
\hline Prostate cancer & 1 & 0 & 3 & 3.13 \\
\hline B-cell lymphoma & 2 & 0 & 2 & 9.38 \\
\hline Melanoma malignum/LMM & 2 & 1 & 1 & 6.25 \\
\hline Acute myeloid leukaemia & 0 & 0 & 1 & 3.13 \\
\hline Chronic lymphocytic leukaemia & 1 & 0 & 1 & 3.13 \\
\hline Hodgkin's lymphoma & 1 & 0 & 1 & 3.13 \\
\hline Thymoma & 1 & 0 & 1 & 3.13 \\
\hline Malignant neoplasm of pyriform sinus & 1 & 0 & 1 & 3.13 \\
\hline Adrenal adenoma & 1 & 1 & 1 & 3.13 \\
\hline Appendicitis cancer & 1 & 0 & 5 & 3.13 \\
\hline Lymphomatoid papulosis & 5 & 6 & 34 & 15.63 \\
\hline Total & 27 & & & \\
\hline
\end{tabular}

Table 3. Cancer distribution by sex

\begin{tabular}{|c|c|c|c|c|c|c|c|c|}
\hline \multirow[t]{2}{*}{ Variable } & \multicolumn{4}{|c|}{ Female $(n=14)$} & \multicolumn{4}{|c|}{ Male $(n=18)$} \\
\hline & Number & $\begin{array}{c}\% \text { MFI } \\
\text { SS }\end{array}$ & $\begin{array}{l}\% \text { other } \\
\text { primary } \\
\text { cancers }\end{array}$ & $\begin{array}{c}\text { Population } \\
\text { (\%) }\end{array}$ & Number & $\begin{array}{c}\% \text { MF/ } \\
\text { SS }\end{array}$ & $\begin{array}{l}\% \text { other } \\
\text { primary } \\
\text { cancers }\end{array}$ & $\begin{array}{c}\text { Population } \\
\text { (\%) }\end{array}$ \\
\hline Lung cancer & 1 & 1.25 & 7.14 & $9.00[4]$ & 3 & 3.09 & 16.67 & $18.70[4]$ \\
\hline Basal cell carcinoma & 2 & 2.50 & 14.29 & $7.50[4]$ & 3 & 3.09 & 16.67 & $6.80[4]$ \\
\hline Breast cancer & 2 & 2.50 & 14.29 & $21.90[4]$ & 0 & 0 & 0 & $0.18[7]$ \\
\hline Ovarian cancer & 1 & 1.25 & 7.14 & $5.00[4]$ & NA & NA & NA & NA \\
\hline Kidney cancer & 1 & 1.25 & 7.14 & $3.00[4]$ & 1 & 1.03 & 5.56 & $4.00[4]$ \\
\hline Bladder cancer & 0 & 0.00 & 0.00 & $2.00[4]$ & 2 & 2.06 & 11.11 & $7.00[4]$ \\
\hline Prostate cancer & NA & NA & NA & NA & 1 & 1.03 & 5.56 & $15.50[4]$ \\
\hline B-cell lymphoma & 1 & 1.25 & 7.14 & $1.90[4]$ & 2 & 2.06 & 11.11 & $2.10[4]$ \\
\hline Melanoma malignum/LMM & 1 & 1.25 & 7.14 & $1.90[4]$ & 1 & 1.03 & 5.56 & $1.70[4]$ \\
\hline Acute myeloid leukaemia & 1 & 1.25 & 7.14 & $0.70[4]$ & 0 & 0.00 & 0.00 & $0.80[4]$ \\
\hline Chronic lymphocytic leukaemia & 0 & 0.00 & 0.00 & $1.00[4]$ & 1 & 1.03 & 5.56 & $1.30[4]$ \\
\hline Hodgkin's lymphoma & 1 & 1.25 & 7.14 & $0.50[4]$ & 0 & 0.00 & 0.00 & $0.50[4]$ \\
\hline Thymoma & 1 & 1.25 & 7.14 & $1.50[5]$ & 0 & 0.00 & 0.00 & $1.50[5]$ \\
\hline Malignant neoplasm of pyriform sinus & 1 & 1.25 & 7.14 & $0.40[4]$ & 0 & 0.00 & 0.00 & $2.70[4]$ \\
\hline Adrenal adenoma & 1 & 1.25 & 7.14 & $0.20[6]$ & 0 & 0.00 & 0.00 & $0.20[6]$ \\
\hline Appendicitis cancer & 1 & 1.25 & 7.14 & $1.20[4]$ & 0 & 0.00 & 0.00 & $1.20[4]$ \\
\hline Lymphomatoid papulosis & 1 & 1.25 & 7.14 & $1.90[4]$ & 4 & 4.12 & 22.22 & $2.10[4]$ \\
\hline
\end{tabular}

NA - not applicable. 


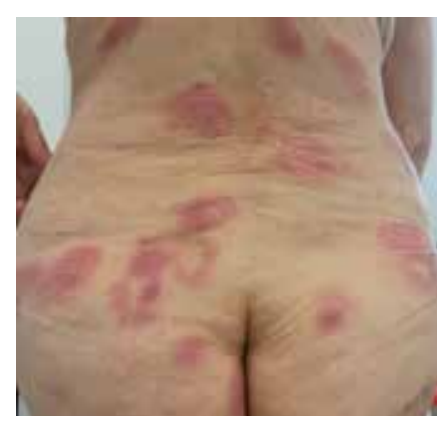

Figure 1. A 80-year-old woman with mycosis fungoides (stage II) and chronic lymphocytic leukaemia

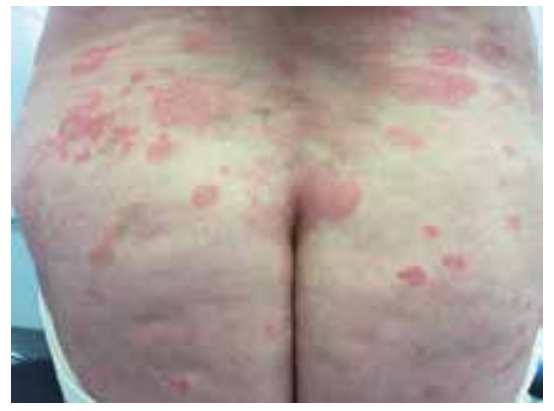

Figure 2. A 67-year-old woman with folliculotropic mycosis fungoides and Hodgkin's lymphoma (mixed cellularity subtype)

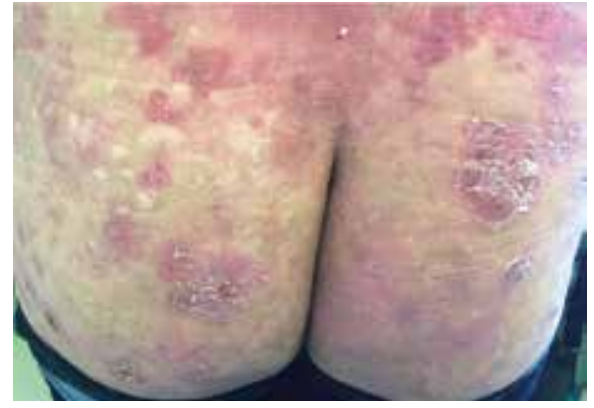

Figure 3. A 49-year-old man with mycosis fungoides (stage IIb) and diffuse large B-cell lymphoma ticularly patients with advanced stage disease or tumours [9]. The results of our study do not support previous findings. The vast majority of the patients were diagnosed with $1 \mathrm{~A}$ and $1 \mathrm{~B}$ stage of mycosis fungoides (respectively, $54.84 \%$ and $19.35 \%$ of patients). Tumour stage and Sezary syndrome was diagnosed in 4 (12.9\%) Patients.

Moreover, we did not notice differences in the clinical picture in patients with concomitant malignancy (Figures 1-3).

Furthermore, the incidence of malignancy was higher within the first year of diagnosis. In the study conducted by Amber et al. an increased risk of Hodgkin's lymphoma development was demonstrated for men, and bronchopulmonary malignancies for women. Generally, their incidence was significantly higher in stage I and IV CTCL while the patients with CD30+ lymphocytes had a higher incidence of Hodgkin's lymphoma, non-Hodgkin's lymphoma, and urinary cancers compared to the general population [10].

Interestingly, patients with MF were also characterized by higher risk of co-occurrence of cutaneous T-cell lymphoma with other hematoproliferative disorders. What is more, the risk of co-existing Hodgkin's disease was highest for patients $\geq 60$ years old. On the other hand, the risk of second non-Hodgkin's lymphoma was highest in patients between 20 and 39 years of age [10].

In this study, a significant association with leukaemias and lymphomas was noticed in the MF group. A diagnosis of B cell lymphoma was found in 3 cases, while 1 patient was diagnosed with chronic lymphocytic leukaemia (CLL).

Additionally, we noticed that MF can be associated with acute leukaemia, specifically myeloid type. Our finding is supported by previous observations [11], but the reason for this association is not fully explained. Some authors suggest that this could be due to the exposure to the alkylating agents that may exert carcinogenic effects [12, 13]. In addition, several reports highlighted that the development of AML can be also associated with psoralen and ultraviolet A (PUVA) treatment [14, 15]. Nevertheless, we reported only 1 case of 41-year-old woman with $\mathrm{AML}$ and MF; however, the leukaemia was diagnosed a year before CTCL, and the patient had never received phototherapy.

This association of co-existence of Hodgkin's lymphomas (HL) and CTCLs was described in 1963 for the first time. Approximately 40 cases have been reported in literature since that time [16]. In this study, the Hodgkin's lymphoma was revealed in a 67-year-old woman who was diagnosed with MF 4 years earlier. Various treatments modalities were defined in her case, including topical steroids, UVB therapy, interferon $\alpha$, and bexarotene, providing only partial and temporary improvements. Subsequently, the HL chemotherapy regimen ABVD (Adriamycin, Bleomycin, Vinblastine, Dacarbazine) was introduced (6 cycles).

It should be noted that the association of MF and $\mathrm{HL}$ has been described several times in the literature. Not only the genetic factors, but also the use of immunosuppressants in the treatment of this cutaneous lymphoma or Epstein-Barr virus infection have been implicated for the development of B-cell lymphoproliferative disorders [13, 17].

The results of this study also support the earlier observations that lymphoma patients are at increased risk of acquiring lung cancer as compared to the general population [17]. This association has been described mainly in anti-lymphoma therapies, although the precise mechanism has not been elucidated yet. In 2 populationbased studies on MF patients from the USA and Finland, Kantor et al. [3] and Väkevä et al. [18] have reported a 2.8- and 2.7-times higher risk of lung cancer, respectively [18]. Additionally, iatrogenic cancer risks in these populations were also considered. There is concern about a possible association between PUVA treatment and an increased risk of non-cutaneous cancer. According to Stern et al. the overall risk of non-cutaneous cancer was nearly identical to that expected in the general population [19]. In 4 out of 32 patients (3 men, 1 woman) lung cancer was diagnosed in our group. The diagnosis of 

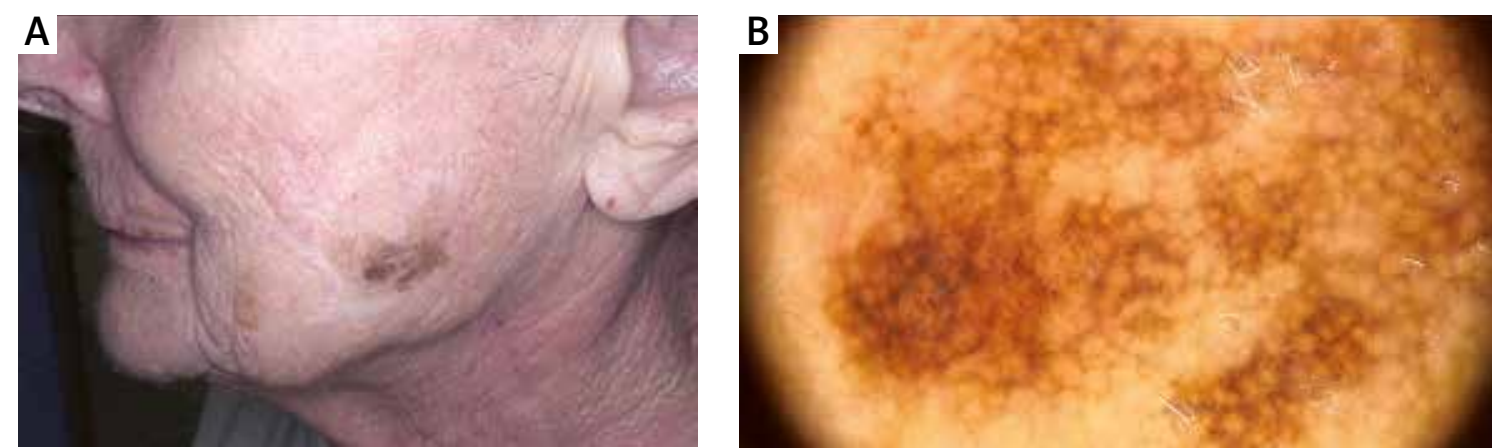

Figure 4. A 89-year-old woman with mycosis fungoides and lentigo maligna melanoma (Breslow $0.5 \mathrm{~mm}$ )
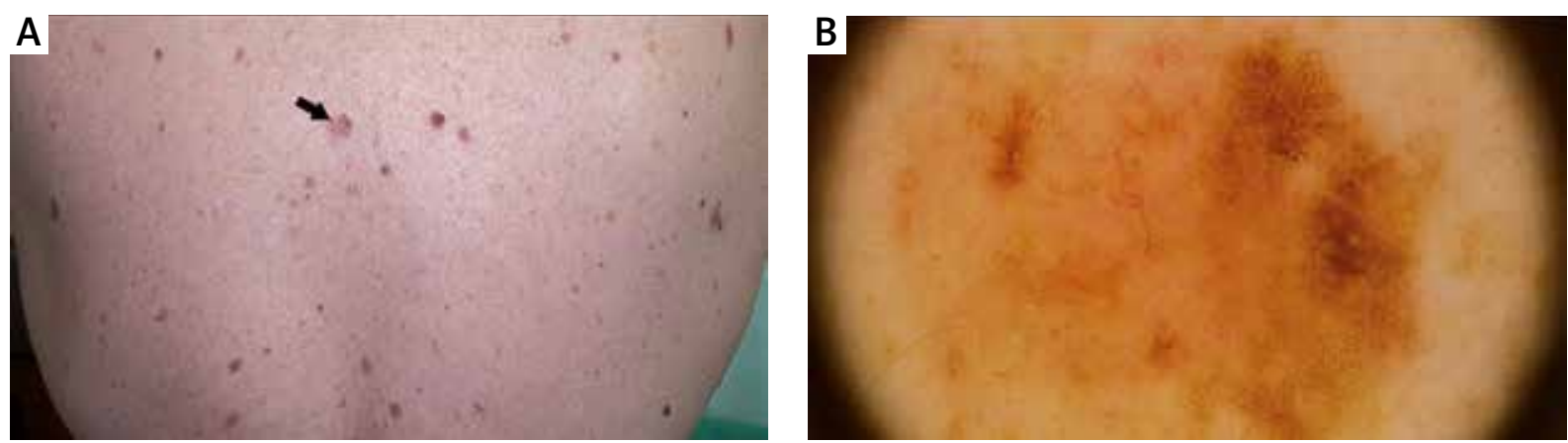

Figure 5. A 54-year-old man with mycosis fungoides and superficial spreading melanoma (Breslow $0.3 \mathrm{~mm}$ )

co-existing cancer was preceded by MF in 3 cases. This association can be related to anti-lymphoma therapy. Although the precise mechanism has not been described, the influence of CTCL treatment to the skin microenvironment is suspected: Th1 to Th2 switch related to downregulation of STAT4 (because of IL-12 deficiency) and upregulation of STAT3 and STAT5 (induced by IL-2 and IL-15 as well as by cytokine independent JAK1/JAK3 signalling). Constitutive STAT3 and STAT5 activation in late stages increases survival and resistance to apoptosis and promotes Th2 and Th17 phenotypes, which is not only important in CTCL progression. CTCL treatment can also influence staphylococcal colonization - and it is well known that peptides produced by staphylococci can also promote the Th1 to Th2 shift. It is also known that tumour microenvironment macrophages (TAMs) contribute the immune suppressive environment and promote tumour growth not only in CTCL [20]. Three of 4 patients were treated systemically in our group: 2 with methotrexate and 1 with bexarotene and interferon $\alpha$.

An elevated rate of malignant melanoma (MM) in patients with MF was also previously noted [21]. In our study, 2 patients were diagnosed with MM after the diagnosis of MF (Figures 4, 5). However, those patients had not received potentially carcinogenic therapy for their MF before the development of MM. The reasons for this association are unclear, but it may involve several factors related to the host or the environment. UV exposure is considered to be a major cause of cutaneous immunosuppression, and it is implicated as an aetiological factor of both melanoma and non-Hodgkin's lymphoma [22, 23]. None of our patients with MF and MM was exposed to phototherapy before the diagnosis. But patients with $M F$ and $\mathrm{HL}$ were exposed to phototherapy before the $\mathrm{HL}$ diagnosis. UV-specific p53 mutations have been detected in MF, particularly in tumour-stage disease [24]. Abnormalities in the p16 gene are also known to be found in MM and CTCL as well $[25,26]$.

\section{Conclusions}

To the best of our knowledge, our study is the first report of the incidence of other primary cancers in Polish patients with cutaneous lymphoma. However, this study has some limitations, such as a small number of cases, along with being a single-centre based study. More patients are needed to shed further light on the association between CTCL and other primary cancers. Generally, for the patients with CTCL, a careful follow-up examination is required to detect other cancers as soon as possible.

\section{Conflict of interest}

The authors declare no conflict of interest. 


\section{References}

1. Huang KP, Weinstock MA, Clarke CA, et al. Second lymphomas and other malignant neoplasms in patients with mycosis fungoides and Sezary syndrome: evidence from population-based and clinical cohorts. Arch Dermatol 2007; 143: 45-50.

2. Sharma P, Goyal S, Yadav AK, et al. Hodgkin's lymphoma arising in a case of mycosis fungoides: an unusual association. Indian J Dermatol Venereol Leprol 2018; 84: 292-7.

3. Kantor AF, Curtis RE, Vonderheid EC, et al. Risk of second malignancy after cutaneous T-cell lymphoma. Cancer 1989; 63: 1612-5.

4. Krajowy Rejestr Nowotworów; onkologia.org.pl

5. Winiarczyk K, Knetki-Wróblewska M, Kowalski DM, et al. Pierwotne nowotwory grasicy obecny stan wiedzy. Onkol Prakt Klin 2012; 8: 209-17.

6. Tupikowski W, Bednarek-Tupikowska G, Florczak A. Rak kory nadnerczy i sposoby jego zwalczania. Postep Hig Med Dośw 2004; 58: 27-36.

7. Gawełko J, Wilk K. Nowotwory. Breast carcinoma in males in the region of southeast Poland in 1963-2011. J Oncol 2015; 65: 103-10.

8. Cengiz FP, Emiroğlu N, Onsun N. Frequency and risk factors for secondary malignancies in patients with mycosis fungoides. Turk J Haematol 2017; 34: 378-9.

9. Goyal A, O'Leary D, Goyal K, et al. Increased risk of second primary malignancies in patients with mycosis fungoides: a single center cohort study. J Am Acad Dermatol 2020; 82: 736-8.

10. Amber KT, Bloom R, Nouri K. Second primary malignancies in CTCL patients from 1992 to 2011: a SEER-based, population-based study evaluating time from CTCL diagnosis, age, sex, stage, and CD30+ subtype. Am J Clin Dermatol 2016; 17: 71-7.

11. Brownell I, Etzel CJ, Yang DJ, et al. Increased malignancy risk in the cutaneous T-cell lymphoma patient population. Clin Lymphoma Myeloma 2008; 8: 100-5.

12. Au WY, Ma SK, Chung LP, et al. Two cases of therapy-related acute promyelocytic leukemia (t-APL) after mantle cell lymphoma and gestational trophoblastic disease. Ann Hematol 2002; 81: 659-61.

13. Green MH, Young RC, Merrill JM, et al. Evidence of a treatment dose response in acute nonlymphocytic leukemias which occur after therapy of non-Hodgkin's lymphoma. Cancer Res 1983; 43; 1891-8.

14. Kwong YL, Au WY, Ng MH, et al. Acute myeloid leukemia following psoralen with ultraviolet A therapy: a fluorescence in situ hybridization study. Cancer Genet Cytogenet 1997; 99: 11-3.

15. Takeoka Y, Yamane T, Koh KR, et al. Mycosis fungoides terminating in acute myelocytic leukemia. Rinsho Ketsueki 2000; 41: 755-60.

16. Block JB, Edgcomb J, Eisen A, et al. Mycosis fungoides. Natural history and aspects of its relationship to other malignant lymphomas. Am J Med 1963; 34: 228-35.

17. Hodak E, Lessin S, Friedland R. New insights into associated co-morbidities in patients with cutaneous T-cell lymphoma (mycosis fungoides). Acta Derm Venereol 2013; 93: 451-5.

18. Väkevä L, Pukkala E, Ranki A. Increased risk of secondary cancers in patients with primary cutaneous T cell lymphoma. J Invest Dermatol 2000; 115: 62-5.

19. Stern RS, Vakeva LH. Noncutanous malignant tumors in the PUVA follow-up study 1975-96. J Invest Dermatol 10997; 108: 897-900.
20. Fujji K. New therapies and immunological findings in cutaneous T-cell lymphoma. Front Oncol 2018; 8: 198.

21. Evans AV, Scarisbrick JJ, Child FJ, et al. Cutaneous malignant melanoma in association with mycosis fungoides. J Am Acad Dermatol 2004; 50: 701-5.

22. Cooper KD, Oberhelman L, Hamilton TA, et al. UV exposure reduces immunization rates and promotes tolerance to epicutaneous antigens in humans (relationship to dose, CDla , DR+ epidermal macrophage induction and Langerhans depletion). Proc Natl Acad Sci USA 1992; 89: 8497-501.

23. Bentam G. Association between the incidence of non-Hodgkin's lymphoma and solar ultraviolet radiation in England and Wales. BMJ 1996; 312: 1128-31.

24. McGregor JM, Crook T, Fraser-Andrews EA, et al. Spectrum of p53 gene mutations suggests a possible role for ultraviolet radiation in the pathogenesis of advanced cutaneous lymphomas. J Invest Dermatol 1999; 112: 317-21.

25. Scarisbrick JJ, Woolford AJ, Calonje E, et al. Frequent abnormalities of the p15 and p16 genes in mycosis fungoides and Sézary syndrome. J Invest Dermatol 2002; 118: 493-9.

26. Navas IC, Algara P Mateo M, et al. P16(INK4a) is selectively silenced in the tumoral progression of mycosis fungoides. Lab Invest 2002; 82: 123-32. 